\title{
Visual Interactive Computer Package for Air Conditioning System Design: Case of the International Conference Centre, University of Ibadan, Nigeria
}

\author{
K. M. Odunfa1, T. O. Arowona1, V. O. Odunfa ${ }^{2}$ \\ ${ }^{1}$ Mechanical Engineering Department, University of Ibadan, Ibadan, Nigeria \\ ${ }^{2}$ Estate Management Department, The Polytechnic, Ibadan, Ibadan, Nigeria \\ Email: tarowona@yahoo.com,m.odunfa@mail1.ui.edu.ng
}

How to cite this paper: Odunfa, K.M., Arowona, T.O. and Odunfa, V.O. (2018) Visual Interactive Computer Package for Air Conditioning System Design: Case of the International Conference Centre, University of Ibadan, Nigeria. Journal of Building Construction and Planning Research, 6, 317-330.

https://doi.org/10.4236/jbcpr.2018.64021

Received: March 19, 2018

Accepted: December 26, 2018

Published: December 29, 2018

Copyright () 2018 by authors and Scientific Research Publishing Inc. This work is licensed under the Creative Commons Attribution International License (CC BY 4.0).

http://creativecommons.org/licenses/by/4.0/

\begin{abstract}
Air conditioning design has become an interesting aspect of human life with the aim of seeking environmental comfort for indoor spaces. Analytical work involves in the design of air-conditioning system is often time consuming and laborious. This work therefore aims at developing a visual interactive computer package for the design of air conditioning system using the international conference centre, University of Ibadan, Nigeria as a case study. Procedures for calculating heat gain through various building components were discussed in detail. Cooling load analysis was carried out using standard cooling load equations obtained from the American Society of Heating, Refrigeration and Air conditioning Engineers (ASHRAE) handbook. A computer program was developed using java programming language to compute the total cooling load in the building. The result from the computer program was obtained within a very short period of time when compared with that of the manual one. The cooling load of the building obtained was 3,194,414 btu/hr; a visual interactive computer package for the design of air conditioning system has been developed and tested positively; hence can be used to design air conditioning system for any building.
\end{abstract}

\section{Keywords}

Environmental Comfort, Programming Language, Air Conditioning Design

\section{Introduction}

Before an air conditioning system is designed and subsequently installed in a 
building, a careful and detailed analysis of the cooling load is important and hence takes preeminence. The energy crises with its drastic escalation of fuel and electric energy costs have made it to be so. In some years back, emphasis was mainly on comfort, but the present trend of things has made the emphasis to be shifted on energy conservation and efficiency [1]. For large and complex air conditioning systems, there is no substitute for a painstaking engineering analysis. This is essentially true when a specific set of indoor condition is to be maintained against a specified set of outdoor conditions. Every variable in the problem should be estimated as accurately as possible so that design conditions will be maintained with the lowest possible energy use. It is therefore of great necessity that the available data is accurate if a high degree of accuracy of land estimation is required. To provide this database, a detailed survey of an existing building or of the plans for a new building is essential factors such as construction materials, orientation of the building [2] [3], occupancy of peak and off-peak conditions, cedes and government regulations together with preliminary consideration of type of system or unit are all important to the load calculation. This project has made design of air conditioning system easier, faster and readily available when compared with the existing other computer programmes in the local market.

\section{Design Procedure}

\section{Air conditioning cooling load analysis}

Spaces to be air-conditioned are continually gaining and loosing heat energy. If the temperature in a given space remains relatively constant for a time, it does not follow that there are no heat gains or losses taking place. A steady temperature merely remains that the rate of heat gains from all sources is equal to the rate of heat loss from the space. It is therefore necessary to determine the air-conditioning cooling or heating loads on an air-conditioning system before such system can be designed for either summer or winter operation. Building and building spaces gain sensible heat in summer and lose it in winter by conduction, convection (ventilation and infiltration), and radiation. They may also gain and lose latent heat (moisture) actually through walls or through cracks around doors and window. Both sensible and latent heat may be produced within conditioned spaces by occupants and by machines and equipment. Lights produce only sensible heat in the space. Thus, in effect, the rate at which heat energy must be supplied to a space to maintain a stipulated design condition in the space is called the HEATING LOAD. Similarly, the rate at which heat energy must be removed from a space in order to maintain a design condition is called the COOLING LOAD. The analysis here has been confined to estimating cooling load [4] [5] [6] since in the Tropics, the temperature is normally above that which will necessitate heating.

Cooling load classification

The space heat gain or instantaneous rate of heat gain is the rate at which 
heat enters and or is generated within a space at a given instant of time. For cooling load analysis in building, the following procedures as developed by the American Society of Heating, Refrigeration and Air-conditioning Engineers (ASHRAE) [7] [8] [9] [10] are employed. The procedures are hereby itemized as follows:

The cooling load calculations deal with heat gains are of two kinds:

1) Sensible heat, which, as it flows into or is produced in a space, will tend to cause a temperature rise in the space.

2) Latent heat, in the form of moisture, which although it does not cause a temperature rise, does change the condition of the air in the space, resulting in a higher humidity.

Sensible heat gain to the space includes:

- Heat transmission through the building structure as a result of conduction, convection and radiation.

- Heat entering the space as a result of solar radiation through windows or other transparent or translucent components.

- Sensible heat brought in as a result of ventilation and infiltration of outside air.

- Sensible heat produced by occupants.

- Sensible heat produced by light, appliances, motors etc.

- Sensible heat to be extracted from material or product brought into the space (industrial air-conditioning).

Latent heat (moisture) gains may be classified as:

- Latent heat from outside air (both that introduced for ventilation and that which infiltrates into the space).

- Latent heat from the occupants.

- Latent heat from cooking, hot baths or moisture producing equipment in the space.

- Latent heat from products or materials brought into the space.

Further load classification, which is frequently used, is based on the source of heat. These are:

1) External Load Loads are external, if they come from without the conditioned space. These may be either sensible or latent.

2) Internal Load Loads become internal if they are produced within the conditioned space. This too may be either sensible or latent.

\section{Building heat transmission}

Heat enters a building by means of conduction, convection and radiation. Conduction and radiation involve sensible and latent heat. Various methods are available for calculating heat gains into and within a conditioned space, but analysis here, has been developed using the currently recommended factor called the cooling load temperature difference (CLTD). Cooling load temperature difference data take into account the design temperature difference, the solar radiation absorbed by the component of construction, the time of day and the variation in outside temperature. It is an equivalent temperature difference used in place of 
the design and inside-outside temperature difference, and it includes solar effects. Tables in ASHRAE Handbook Fundamentals [8] provide cooling load temperature differences (CLTDs) for several walls or roof constructions.

\section{Heat transmission through roofs}

Solar radiation is almost always a factor on roofs, and since roofs may account for as much as 50 percent of the total summer load, it is important to estimate this load rather accurately. Hence the relation gives the heat transmitted through the roof,

$$
q_{s}=U^{*} A^{*} C L T D,
$$

where $U=$ coefficient of heat transmission of roof.

$A=$ roof area and $C L T D=$ Cooling Load Temperature Difference of base condition for roof.

\section{Heat gain through walls}

The relation below gives the heat gain through the wall:

$$
q_{s}=U * A * C L T D
$$

This is sometimes called the wall leakage load and it is a measure of heat when leaks through the walls of the air-conditioned space from the outside into the inside, since there is no perfect insulation. There is always a certain amount of heat passing from the outside to the inside whenever the inside temperature is below that of the outside. The CLTD is corrected for color of exterior surface, corrections for inside and outside dry bulb temperature and correction for latitude and month. The corrected cooling load temperature difference (CLTD) is given by:

$$
C C L T D=(C L T D+L M) K+\left(25.5-T_{R}\right)+\left(T_{0}-29.4\right)
$$

where $\mathrm{LM}=$ Latitude-Month correction.

$K=$ color adjustment.

$K=1.0$ if dark colored or light in an industrial area.

$K=0.83$ if permanently medium-colored (rural area).

$K=0.65$ if permanently light colored (rural area).

$\left(25.5-T_{R}\right)$ is indoor design temperature correction.

$\left(T_{0}-29.4\right)$ is the outdoor design temperature correction.

\section{Solar heat gain}

There are various factors, which affect the value of direct solar radiation. These include; time of day, orientations of the different glass windows and altitude of the sun itself. Some radiation occurs from the sky itself, even though the direct rays of the sun do not strike the surface in question. Because of the various factors just mentioned, which affect the radiation from the sun, the solar heat gain for this cooling load analysis, depends heavily on the results from experiment performed by ASHRAE researchers in which they obtained solar heat gain factor (SHGF) for daylight hours of the twenty-first day of each month, and for seventeen principal orientations. Thus in effect, for any shading device(s) incident angle, solar radiation intensity and glass orientation, the heat gain due to solar radiation is given by; 


$$
q=A^{*} S C^{*} S H G F^{*} C L F
$$

where

$S C=$ shading coefficient.

$S H G F=$ Solar heat gain factor.

$C L F=$ cooling load factor.

\section{Heat gain due to lighting}

Cooling load due to lighting system is often the space load component. Some of the energy emanating from light is form of radiation which only affects the air after it has been absorbed by the walls, floors and furniture and has warmed to a temperature higher than the air temperature. The absorbed energy stored by the structure contributes to the space cooling load after a time lag.

The instantaneous rate of heat gain from electric lighting in wall is given as; $q=$ Total light wattage $*$ Usefactor $*$ special allowance factor

The cooling load due to light is then obtained from:

$$
\text { Heatgain }=q^{*} C L F
$$

where $C L F$ is the cooling load factor for light.

\section{Heat gain due to occupancy}

Human beings give off heat at a metabolic rate which depends on their rate of activities. The sensible and latent portion of the heat liberated for any given activity depends on the value of the ambient dry-bulb temperature. The lower the dry-bulb temperature, the larger the portion of sensible heat dissipated.

The sensible heat gain from occupants is:

$$
q_{s}=N o * S H G * C L F \text { and }
$$

the latent heat gain from occupant is

$$
q_{L}=N o * L H G
$$

where

$N_{O}=$ number of occupants.

$S H G=$ Sensible heat gain from occupants as a measure of their degree of activities.

$L H G=$ Latent heat gain from occupants.

CLF Cooling Load Factor for people based on duration of occupancy and time from entry.

\section{Heat gain from appliances}

In cooling load estimation, the heat gain from all heat-producing appliances must be taken into account. The most common heat producing appliances found in conditioned areas are those used for food service establishments, schools, hospitals etc. Experiments have shown that:

1) The heat is primarily radiant energy from appliance surfaces and cooking utensils.

2) Convective and latent heat is negligible when appliances are installed under an effective hood. 
The heat gain from appliances can be obtained from the following expressions:

Sensible heat gain

$$
q_{s}=\text { Heatgain } * C L F
$$

Latent heat gain

$$
q_{L}=\text { Heatgain } * C L F
$$

\section{Ventilation}

Outdoor air must be introduced for ventilation of conditioned space. The outdoor air required primarily depends on the number of occupants and or materials and apparatus within the space that may give off odours, except in industrial and laboratory system requiring large amount of supply air to offset exhaust. The cooling load due to introduction of outdoor air for ventilation can be determined once the indoor and the outdoor design conditions are fixed.

The sensible heat given due to ventilation is given as:

$$
q_{s}=1.232 * \frac{L}{S} * \Delta T
$$

and the latent heat gain can be determined from

$$
q_{L}=3012 * \frac{L}{S} * \Delta W
$$

\section{Infiltration}

Outside air filters into a conditioned space, even though the space may be slightly pressurized by an excess of air supplied over air extracted.

Infiltration is principally due to:

1) Wind pressure, particularly tall commercial buildings.

2) Stack effect.

The heat gain due to infiltration air can then be obtained from the following expressions.

$$
\begin{aligned}
& q_{s}=C F M * \frac{L}{S} * \Delta T(\text { sensible }) \\
& q_{L}=C F M * \frac{L}{S} * \Delta W(\text { Latent })
\end{aligned}
$$

where

$\frac{L}{S}=$ ventilation and infiltration requirements or no of air changed per second.

$\Delta T=$ sensible-outside air temp differences, ${ }^{\circ} \mathrm{C}$.

$\Delta W=$ Inside-Outside air humidity ratio difference, $\mathrm{kgH}_{2} \mathrm{O} / \mathrm{kg}$ dry air.

The main program was written in codes and the language of coding is JAVA. It was developed in such a way that the main program was divided into subprogram known as SUB-ROUTINES (Figure 2). 


\section{Sub-routines}

Each Subroutine takes care of heat gain by the building from the various load components.

Generally, there is a call to each of these sub-routines in terms and the total heat gain by the building which is the cooling load required is the summation of the heat gain from various load components. The following subroutines could be found in the main program:

- SUB ROOFGAIN

- SUB WALLGAIN

- SUB LIGHTGAIN

- SUB GLASSGAIN

- SUB APPLIPGAIN

- SUB OCCUPGAIN

- SUB INFILTGAIN

- SUb TOTALGAin

\section{Results}

\section{Cooling Load Estimate}

The case study description is in Table 1, while its psychrometric analysis is as shown in Table 2. Cooling load consists of the followings: Transmission load (Table 3), solar radiation load (Table 4), internal load (Table 5), Occupancy load (Table 6) and Ventilation/infiltration load (Table 7). The total estimated load for the building is the summation of all types of loads itemized above; detail of the summation is as shown below.

\section{Total cooling load estimated in Watts}

$$
51,726.18 \mathrm{~W}+82,753.1 \mathrm{~W}+6251 \mathrm{~W}+148,200 \mathrm{~W}+10,546 \mathrm{~W}=299,476.28 \mathrm{~W}
$$

Table 1. Case study description.

\begin{tabular}{cc}
\hline Study Title & $\begin{array}{c}\text { DEVELOPMENT OF VISUAL INTERACTIVE COMPUTER } \\
\text { PACKAGE FOR AIR CONDITIONING SYSTEM }\end{array}$ \\
\hline Case study Name & THE INTERNATIONAL CONFERENCE CENTRE (see Figure 1) \\
Purpose & EVENT HALL \\
Month & JUNE \\
Location & UNIVERSITY OF IBADAN \\
\hline
\end{tabular}

Table 2. Psychrometric analysis.

\begin{tabular}{cccccc}
\hline Item & $\mathrm{T}_{\mathrm{db}}$ & $\mathrm{T}_{\mathrm{wb}}$ & $\mathrm{RH}$ & Enthalpy(h) & Specific humidity $(\mathrm{w})$ \\
\hline Outside & 33 & 28 & 50 & & \\
Inside & 22 & 22 & 50 & & \\
Difference & 11 & 6 & & \\
Daily range & 7 & & & \\
\hline
\end{tabular}




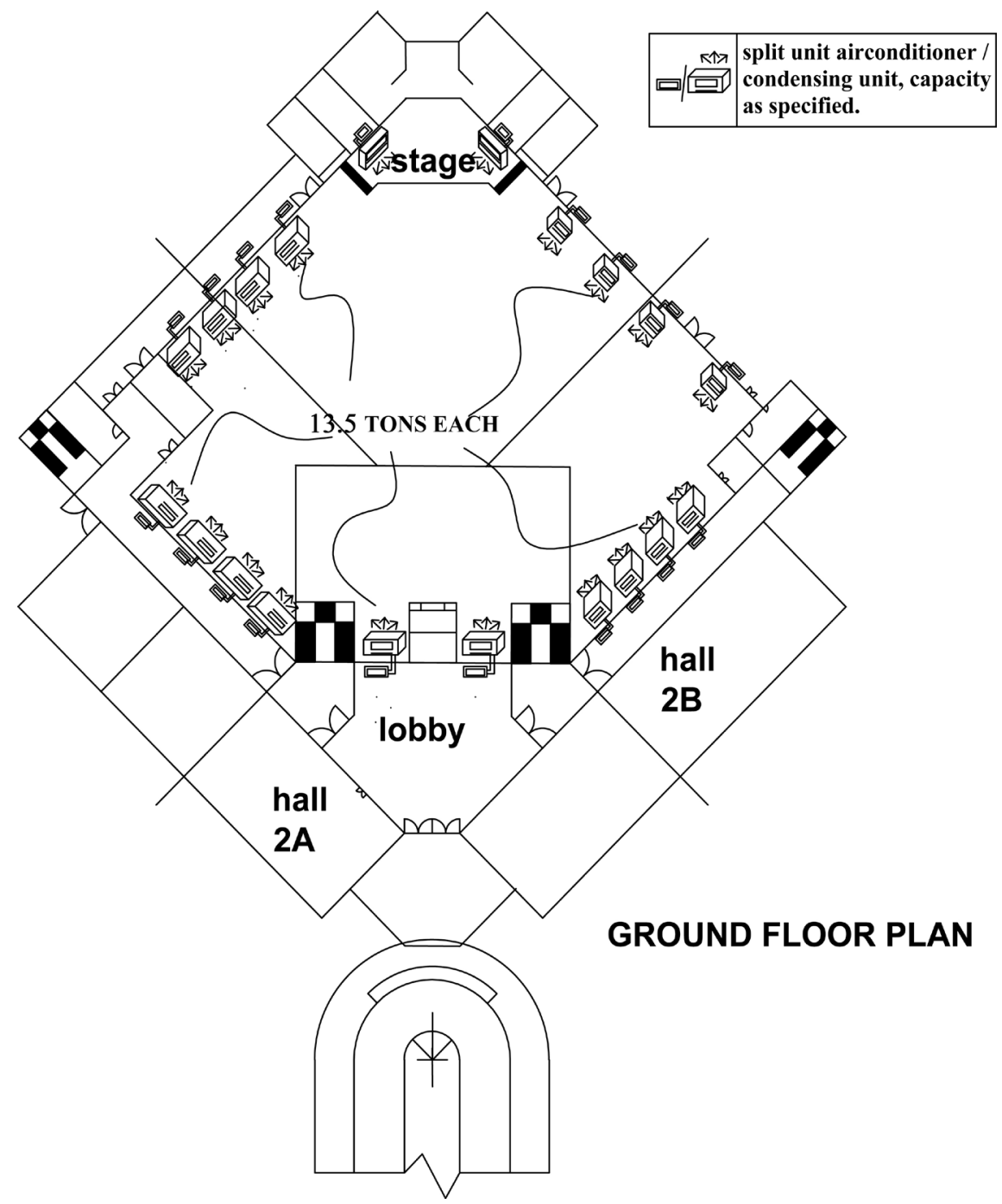

Figure 1. International conference center, University of Ibadan, Ibadan, Nigeria.

Table 3. Transmission load estimate.

\begin{tabular}{cccccc}
\hline \multirow{2}{*}{ Item } & Description & Area $\left(\mathrm{m}^{2}\right)$ & U factor & CLTD & $\mathrm{Q}_{\text {transmission }}(\mathrm{W})$ \\
\hline \multirow{2}{*}{ Walls } & North & 85.64 & 1.86 & 9.375 & 1493 \\
& South & 85.64 & 1.86 & 5.307 & 845 \\
& East & 85.64 & 1.86 & 6.708 & 1068 \\
& West & 85.64 & 1.86 & 9.207 & 1467 \\
\multirow{2}{*}{ Roof } & & 1936 & 0.761 & 23.66 & $34,858.18$ \\
& Norths & 68.02 & 5.9 & 8 & 3210 \\
& South & 68.02 & 5.9 & 8 & 3210 \\
& East & 68.02 & 5.9 & 8 & 3210 \\
& West & 68.02 & 5.9 & 8 & 3210 \\
& & & & TOTAL & $51,726.18 \mathrm{~W}$ \\
\hline
\end{tabular}


Table 4. Solar radiation load estimate.

\begin{tabular}{cccccc}
\hline Description & Area $\left(\mathrm{m}^{2}\right)$ & SC & SHGF & CLF & Q $_{\text {SHG }}(\mathrm{W})$ \\
\hline North & 68.02 & 0.94 & 347 & 0.76 & $16,861.9$ \\
South & 68.02 & 0.94 & 120 & 0.76 & 5831.2 \\
East & 68.02 & 0.94 & 618 & 0.76 & 30,030 \\
West & 68.02 & 0.94 & 618 & 0.76 & 30,030 \\
& & & & TOTAL & $82,753.1 \mathrm{~W}$ \\
\hline
\end{tabular}

Table 5. Internal loads estimate.

\begin{tabular}{cccc}
\hline Item & Input(W) & CLF & Q $_{\text {appliances }}$ \\
\hline Lights & 3600 & 0.88 & 3168 \\
Appliances & 3280 & 0.94 & 3083 \\
& & TOTAL & $6251 \mathrm{~W}$ \\
\hline
\end{tabular}

Table 6. Occupancy load estimate.

\begin{tabular}{cccccc}
\hline & Number of occupants & Heat gain & CLF & $\mathrm{Q}_{\mathrm{L}}$ & $\mathrm{Q}_{\mathrm{S}}$ \\
\hline Sensible & 1300 & 65 & 0.95 & & 80,275 \\
Latent & 1300 & 55 & 0.95 & 67,925 & \\
& & & & TOTAL & $148,200 \mathrm{~W}$ \\
\hline
\end{tabular}

Table 7. Ventilation/infiltration load estimate.

\begin{tabular}{cccccc}
\hline & $\mathrm{L} / \mathrm{s}$ & CFM & $\Delta \mathrm{T}$ & $\mathrm{Q}_{\mathrm{L}}$ & $\mathrm{Q}_{\mathrm{s}}$ \\
\hline Sensible & 0.5 & 1.232 & 7 & & 4.312 \\
Latent & 0.5 & 3012 & 7 & 10,542 & \\
& & & & TOTAL & $10,546 \mathrm{~W}$ \\
\hline
\end{tabular}

$$
\begin{gathered}
750 \mathrm{~W}=8000 \mathrm{Btu} / \mathrm{hr} \\
299,476.28 \mathrm{~W}=3,194,414 \mathrm{Btu} / \mathrm{hr} . \\
1.0 \mathrm{TON}=12,000 \mathrm{Btu} / \mathrm{hr}=266 \mathrm{TONS}
\end{gathered}
$$

20 Nos Packaged Split Unit air-conditioner, each of 13.5 TONS capacity.

These 20 Nos packaged unit air-conditioners are as arranged in Figure 1 for the purpose of uniform distribution of the conditioned air within the cooling space.

\section{Conclusions}

The program presented in this study work is accurately within the scope of its limitations. A lot of effort has been made to reduce the number of inputs required for efficient running of the program. However it has proved to be more reliable and versatile than the previous attempt at this.

It is therefore recommended that further attempts could be directed at the following: 


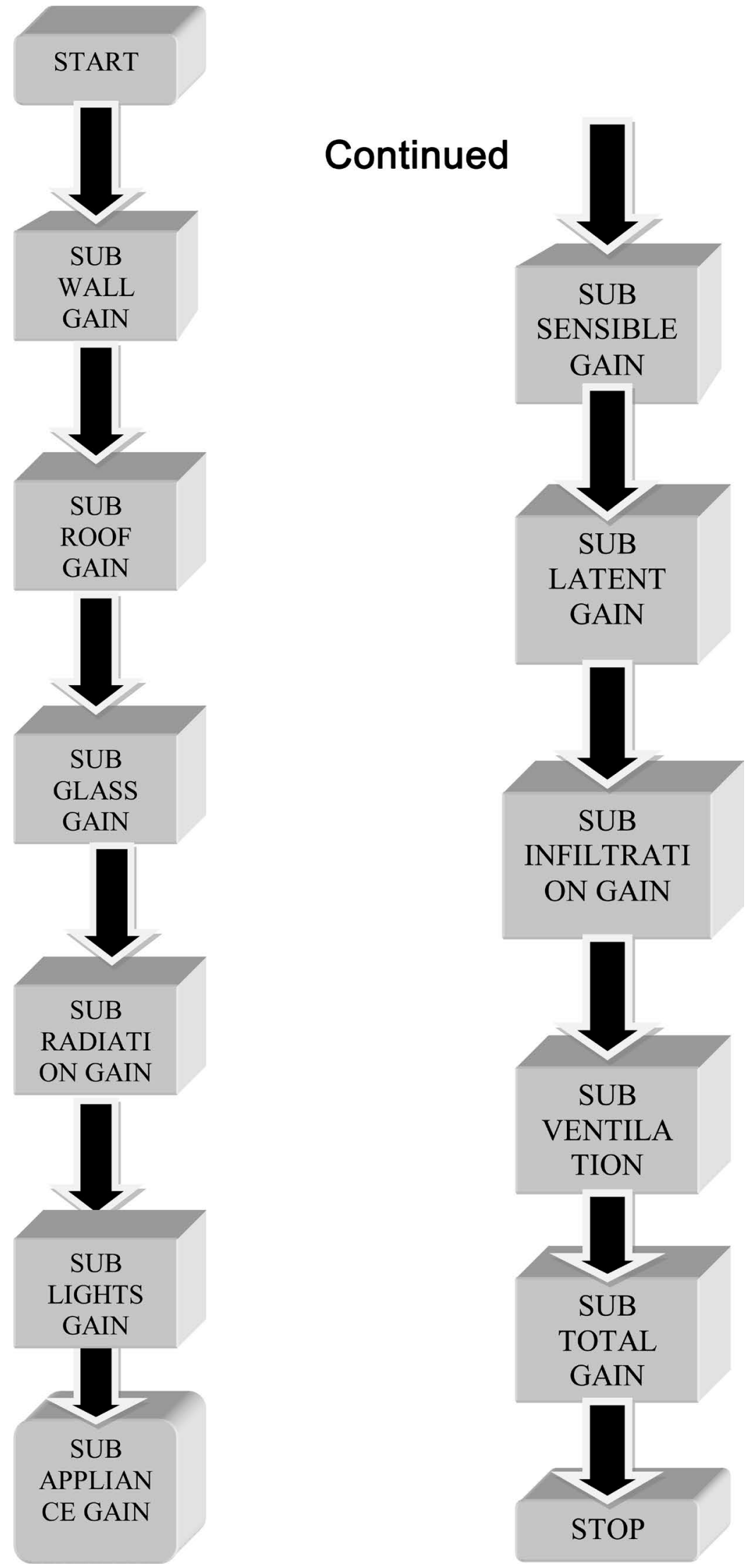

Figure 2. Flow chart for program. 

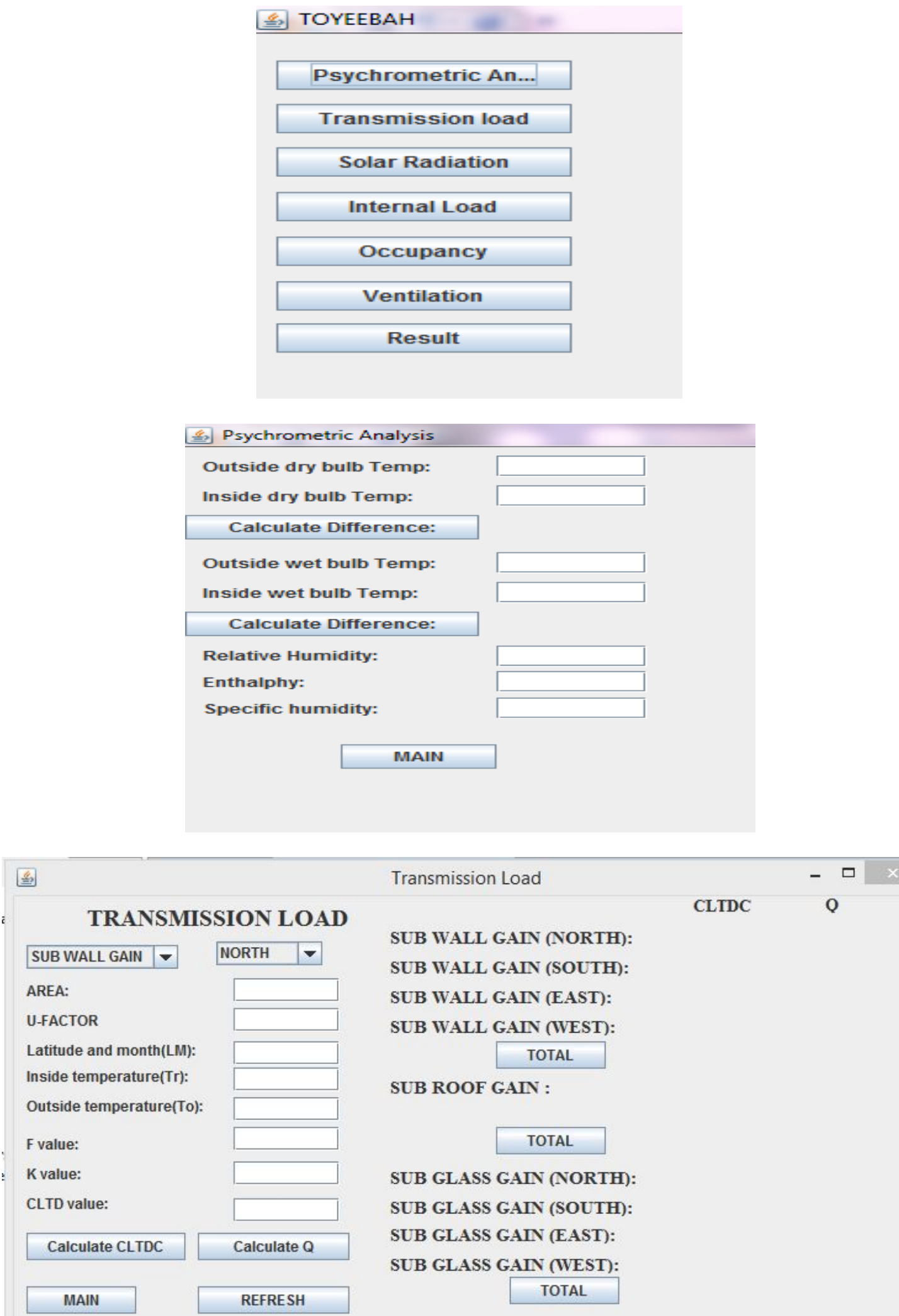

SUB WALL GAIN (NORTH):

SUB WALL GAIN (SOUTH):

SUB WALL GAIN (EAST):

SUB WALL GAIN (WEST):

TOTAL

SUB ROOF GAIN :

$$
\text { TOTAL }
$$

SUB GLASS GAIN (NORTH):

SUB GLASS GAIN (SOUTH):

SUB GLASS GAIN (EAST):

SUB GLASS GAIN (WEST):

TOTAL 
SOLAR RADIATION

NORTH

AREA OF RADIATION: SHADING CO_EFFICIENT: SOLAR HEAT GAIN FACT... COOLING LOAD FACTOR:

Calculate $\mathbf{Q}$

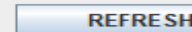

MAIN

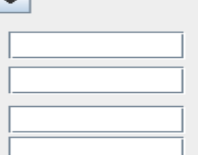

SOLAR RADIATION NORTH):

SOLAR RADIATION (SOUTH):

SOLAR RADIATION (EAST):

SOLAR RADIATION (WEST):

TOTAL

Internal Load

SUB LIGHT GAIN

TOTAL POWER OF LIGHTS (WAT . COOLING LOAD FACTOR:

Calculate $Q$

REFRESH

SUB APPLIANCES GAIN

TOTAL POWER OF APPLIANCES:
(WATTS) COOLING LOAD FACTOR:

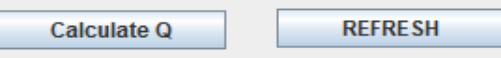

MAIN

SUB LIGHT GAIN:

SUB APPLIANCE GAIN:

Occupancy

OCCUPANCY

SUB SENSIBLE HEAT GAIN

NUMBER OF PEOPLE:

SENSIBLE HEAT FROM OCCUP...

COOLING LOAD FACTOR:

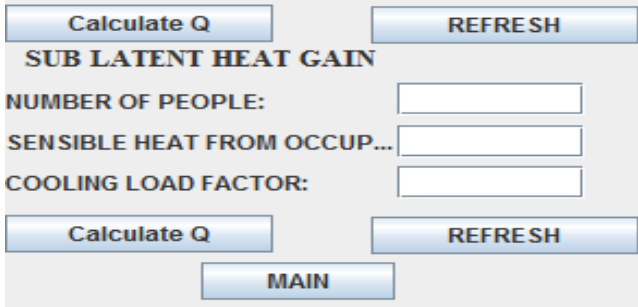

SUB SENSIBLE HEAT GAIN:

SUB LATENT HEAT GAIN: 


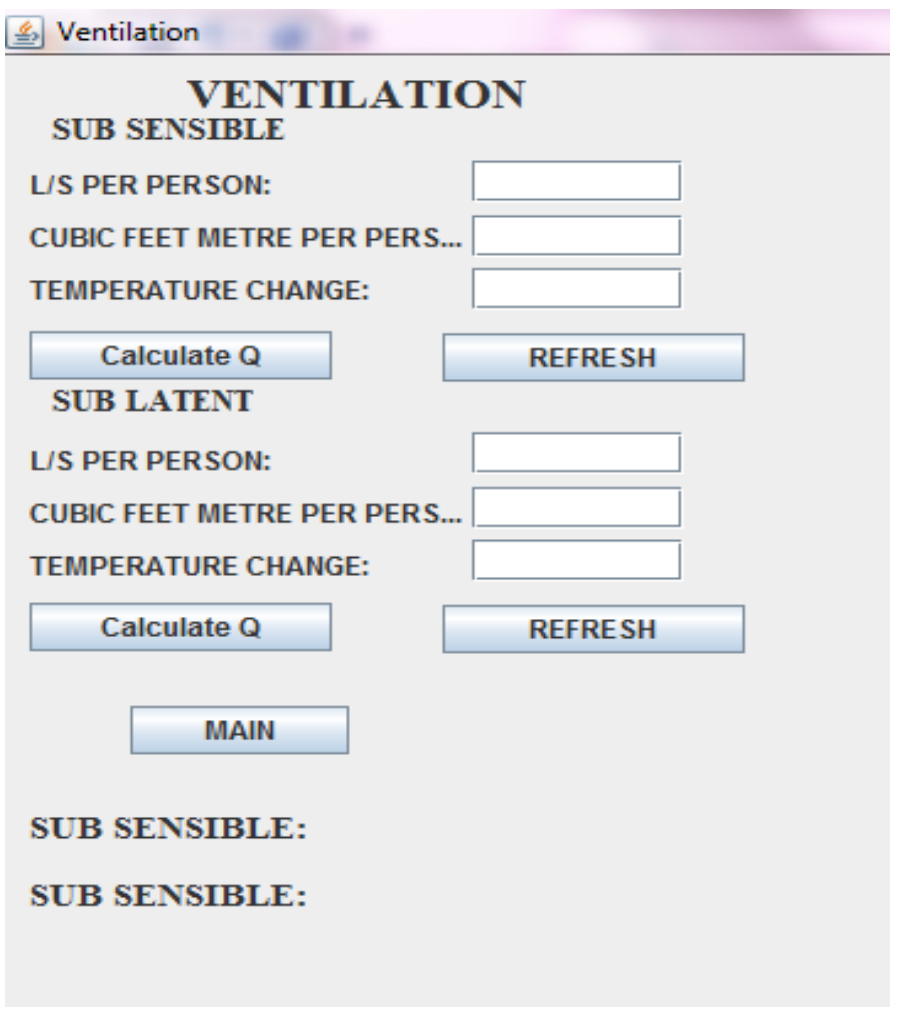

Figure 3. Program interface.

1) Reducing the number of inputs supplied to the computer, which will definitely reduce the time of analysis.

2) Making the program to be more interactive [4] [11] [12] including a standard user friendly menu options.

The developed program displayed (Figure 3 ) in this work can be used for design of any building project, at ease because of the user interface and the simplicity of the program, it is a faster means and better for engineers to avoid the use of rule of thumb which is less accurate when trying to get appropriate and proper cooling system design.

\section{Conflicts of Interest}

The authors declare no conflicts of interest regarding the publication of this paper.

\section{References}

[1] Nwofe, P.A. (2014) Need for Energy Efficient Buildings in Nigeria. International Journal of Energy and Environmental Research, 2, 1-9.

[2] Odunfa, K.M., et al. (2013) Effect of Building Orientation on Energy Conservation. Online Journal of Architecture and Building Technology, 1, 1-5.

[3] Odunfa, K.M., Ojo, T.O., Odunfa, V.O. and Ohunakin, O.S. (2015) Energy Efficiency in Building: Case Study of Buildings at the University of Ibadan, Nigeria. Journal of Building Construction and Planning Research March, 3, 18-26. https://doi.org/10.4236/jbcpr.2015.31003 
[4] (1997) A/C Equipment Efficiency, Heating, Ventilation, Air-Conditioning and Refrigeration News, 10 November 1997.

[5] Khurmi, R.S. and Gupta, J.K. (2006) A Text Book of Refrigeration and Air Conditioning. S. Chand, New Delhi.

[6] Stoecker W.F. and Jones, J.W. (1999) Refrigeration and Air-Conditioning. 3rd Edition, Butterworth-Heinemann, Oxford.

[7] Viswambharan, A. and Patidar, S.K. (2014) Sustainable HVAC Systems in Commercial and Residential Buildings. International Journal of Scientific and Research Publications, 4, 1-4.

[8] American Society of Heating, Refrigerating and Air Conditioning Engineers, Inc. (2013) ASHRAE Hand Book, Refrigeration Fundamentals. SI Edition, American Society of Heating, Refrigerating and Air Conditioning Engineers, Inc., Atlanta.

[9] Durojaiye, O. (2004) Development of a Computerized Package for Air Conditioning System. Final Year B.Sc Project.

[10] Pita, E.G. (1998) Air Conditioning Principles and Systems. 3rd Edition, Eastern Economy Edition.

[11] Adesope, L. (2000) Development of a Computer Program for the Analysis of Energy of Buildings. Final Year B.Sc Project.

[12] American Society of Heating, Refrigerating and Air-Conditioning Engineers Inc. (1985) ASHRAE Handbook 1985 Fundamentals. American Society of Heating, Refrigerating and Air-Conditioning Engineers Inc., Atlanta. 